\title{
Update on the Management of Morbid Adherent Placenta
}

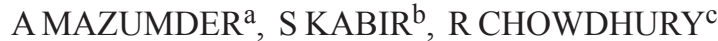

Summary:

Morbid adherent placenta collectively includes placenta accrete, increta, and percreta, according to the depth of invasion through the decidua-myometrial junction. Incidence is increasing due to increase in the incidence of scarred uterus. Scarred either due to caesarean section, myomectomy or repeated $D \& C$. These conditions are responsible for massive obstetrics haemorrhage, associated complications like consumption coagulopathy, multisystem organ failure \& death. Also there is a risk for peripartum

surgical complication, such as injury to the bladder, ureter \& bowel. There is also the need for relaparotomy, complication of blood transfusion, admission in intensive care unit. Indicated or emergency preterm delivery needs

\section{Introduction:}

Obstetrics haemorrhage is one of the important causes of maternal death and morbidity. This morbidity and mortality is not always predictable or preventable. But advancement in obstetrics helps to identify the factors that are responsible for such unexpected events. Morbid adherent placenta which includes spectrum of placenta accreta, increta and percreta, is responsible for massive haemorrhage, associated multi system organ failure, acute respiratory distress syndrome, disseminated intravascular coagulation and death ${ }^{1,2}$. Morbid adherent placenta occurs when placenta is abnormally adherent to the underlying myometrium, in the absence of decidua basalis. Abnormal vascularisation following

a. Dr. Afroza Mazumder, Associate Prof. Gynaecology \& Obstetrics, Bangabandhu Memorial Hospital (BBMH), University of Science and Technology (USTC).

b. Dr. Shanjida Kabir, Asst. Prof. Gynaecology \& Obstetrics, Bangabandhu Memorial Hospital (BBMH), University of Science and Technology (USTC).

c. Dr. Raiq Chowdhury, MD (Course), Haematology, Bangabandhu Sheikh Mujib Medical University (BSSMU), Dhaka.

Address of Correspondence: Dr. Afroza Mazumder, Associate Prof. Gynaecology \& Obstetrics, Bangabandhu Memorial Hospital (BBMH), University of Science and Technology (USTC), E-mail: dr.afrozaustc@gmail.com

Received: 10 January, 2018

Accepted: 10 October, 2018 admission of the newborn to neonatal intensive care unit. Outcome can be improved by multi disciplinary expertise and experienced approach for delivery, including the conservative management to avoid peripartum hysterectomy. Such team approach by maternal-fetal medicine, gynaecological surgeon, vascular, trauma, urology surgeon, transfusion medicine, intensivist, neonatologist, intervention radiologist, anaesthesiologist, specialized nursing staff and ancillary personnel.

Key words: morbid adherent placenta, conservative management, obstetric haemorrhage.

(J Bangladesh Coll Phys Surg 2019; 37: 30-34)

DOI: http://dx.doi.org/10.3329/jbcps.v37i1.39289

uterine scarring, with secondary localised hypoxia leading to defective decidualisation with excessive trophoblastic invasion ${ }^{3}$.

Incidence of morbid adherent placenta is increasing in all countries, $<1$ in 2000 live birth in 1980 and now it is 1 in 500 live birth in 2002. This increase is thought to be the outcome of concomitant rise in the rate of caesarean section, either primary or repeat ${ }^{4}$.

The aim of this review article is to give emphasis on the need for antenatal diagnosis of placental invasion and formulating the plan of management before any emergency arises; to provide an overview of the conservative method of management and to discuss the clinical implication of this condition for both the patient and the clinician. Also to identify the area for further research.

Risk factors for morbid adherent placenta

1. Prior caesarean delivery specially multiple

2. Placenta previa

3. $\mathrm{H} / \mathrm{O}$ uterine surgery including endometrial ablation

4. $1^{\text {st }}$ and $2^{\text {nd }}$ trimester vaginal bleeding with other risk factors. 
One prospective study revealed that the risk of placenta accrete was 3\% in women with placenta previa and no prior caesarean, but $11 \%$ in women with placenta previa with one previous caesarean. The risk increases to $40 \%$ in those with 2 caesarean section and is $>60 \%$ in those with 3 prior caesarean section. But risk of accrete is $1 \%$ in woman with 3 or more caesarean and no placenta previa $^{5}$.

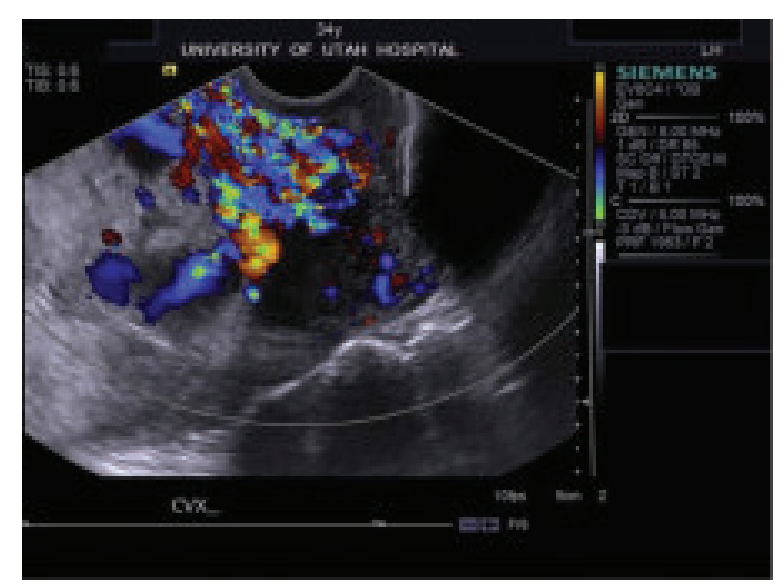

Fig.-1:

Ultrasound findings suggestive of morbid adherent placenta

In $\mathbf{1}^{\text {st }}$ trimester:

i. Gestational sac located in the lower uterine segment

ii. Multiple irregular vascular spaces noted within the placental bed

iii. Implantation of gestational sac embedded into the caesarean scar.

In $2^{\text {nd }}$ trimester:

Multiple vascular lacunae within the placenta

\section{In $3^{\text {rd }}$ trimester:}

i. Loss of normal hypo echoic retro-placental zone,

ii. presence of multiple vascular lacunae within the placenta (Swiss cheese appearance)

iii. Abnormalities in the uterine serosa bladder interface (interruption of line, thickening of line, irregularities of line \& increased vascularity)

iv. Extension of villi into myometrium, serosa or bladder v. Retro-placental myometrial thickness $<1 \mathrm{~mm}$

vi. Doppler study showing evidence of turbulent blood flow through the lacunae, increased subplacental vascularity, vessels bridging from placenta to uterine margins, gaps in myometrial blood flow ${ }^{6}$.

vii. Obstetric sonography has been noted to be quite accurate for the diagnosis of placenta accrete, sensitivity ranges from $77 \%-97 \%{ }^{7}$.

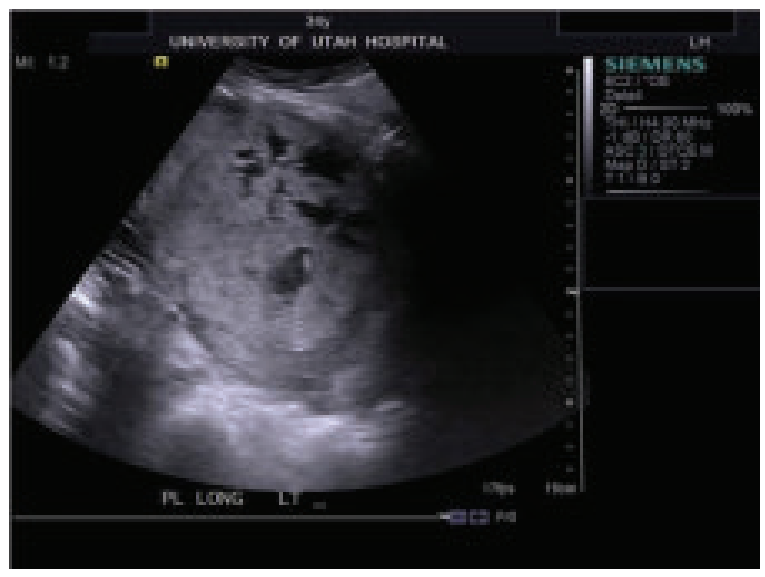

Fig.-2:

viii. MRI may be useful for antenatal diagnosis with $88-89 \%$ sensitivities, and about $88-100 \%$ specificity.

ix. According to Eunice Kennedy Shriver Institute for child health \& human development workshop concluded that USG should be primary for diagnosis, MRI should not be done routinely. MRI may be useful in the cases of placenta previa, to assess the extent of invasion into the adjacent organ \& in case of posterior previa if USG is non diagnostic $^{8}$.

x. Unexpected placenta accreta can be seen following laparotomy by viewing increasing tortuous vessels along the uterine surface, placenta extent at or beyond the lower uterine segment ${ }^{9}$.

Management of morbid adherent placenta remains uncertain with regard of timing of delivery \& optimal surgical approach. Surgical principle includes avoiding disruption of the hypervascular placenta, stepwise devascularisation, early comprehensive blood transfusion and judicious use of intervention radiologic technique such vascular embolization ${ }^{10.11}$. 


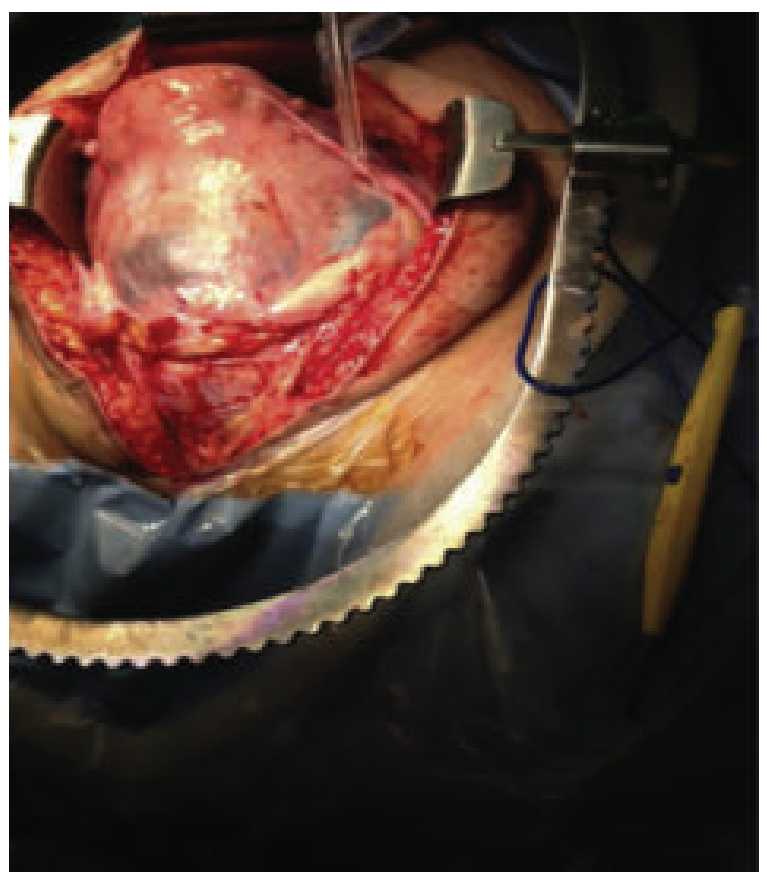

Fig.-3:

Studies show that $50 \%$ cases can be diagnosed by antenatal USG. Indicated preterm delivery at 34-35 weeks of gestation has been proposed as a means to decrease the risk of having emergency surgery as there is an increasing risk of spontaneous bleeding on $>34$ weeks of gestation ${ }^{12}$.

According to a study conducted in Texas, 57 out of 90 cases were managed by multi disciplinary accreta team and delivery was done at 34-35 weeks, which decreased the incidence of emergency surgery significantly ${ }^{13}$. Many cases progress upto 36 weeks of gestation without any complications but issue remain controversial. Conservative management included resection of that portion of anterior uterine wall that includes the morbid adherent placenta followed by uterine reconstruction, caesarean delivery without removal of placenta, closure of hysterotomy and expectant management with the placenta in situ, caesarean hysterectomy ${ }^{14}$.

\section{Uterine Sparing Techniques.}

Placenta kept in situ, umbilical cord ligated close to the placental insertion, along with adjunctive procedure such as use of uterotonics, compression sutures, ballon tamponade, uterine artery embolization or ligation, may reduce uterine perfusion, decrease $\mathrm{PPH}$, and hasten placental reabsorption or sloughing \& expulsion ${ }^{15}$. Time of spontaneous resolution from 9-12 months, with a mean 6 months, but delayed complications are haemorrhage, DIC, endomyometritis, sepsis, reported as major complications. Rare morbidity such as uterocutaneous fistula, choriocarcinoma ${ }^{16}$.

On of the largest retrospective study shows among 167 cases 36 cases needs subsequent hysterectomy due to PPH, 10 patients suffer from severe morbidities like septic shock, Vesico-uterine fistula \& uterine necrosis. Most of the maternal deaths were recorded to be due to complication following use of methotrexate \& fertility outcome was not recorded ${ }^{17}$.

Hysteroscopic resection of placental remnant has been described to expedite the resolution or treat bleeding or pelvic pain. Studies show in $1^{\text {st }}$ series, 4 women who were managed conservatively underwent hysteroscopy, recovered within 1 week of procedure. 2 out of 4 cases subsequently conceived $\&$ delivered by caesarean delivery without any evidence of accrete. In $2^{\text {nd }}$ series 12 women underwent hysteroscopy, for remaining placenta accrete using bipolar cautery with USG guidance. Result shows complete resolution occurs after single procedure in 5 patients (42\%), after 2 attempts in 2 patients (17\%), 3 attempts in 4 patients (30\%). One patient required hysterectomy due to haemorrhage after $1^{\text {st }}$ resection. Patient menstruations resumes and 4 subsequently become pregnant with 2 live birth ${ }^{18}$.

Placental - Myometrial En Block Excision \& Repair En Block excision of placenta accreta was first described by palacios et al, in 2004 in a series of 68 cases $^{19}$. This technique permitted resection of invaded myometrium when $50 \%$ or less of the anterior uterine circumference is invaded. After excision the resulting defect was repaired with myometrial pulley suture, similar to horizontal mattress suture. The defect was covered with absorbable mesh. Uterine conservation was completed in 50 of 68 women (74\%). Of this 42 had 3 years follow up- 10 become pregnant and were delivered at 36 weeks with schedule caesarean section \& even with these technique 18 patient $(26 \%)$ needs hysterectomy ${ }^{20}$.

\section{Adjunctive Procedure}

Arterial Occlusion \& Methotrexate Administration. Arterial occlusion temporarily reduce blood $\operatorname{loss}^{21}$, but due to rich collateral feeding vessels arising from 
cervico-vaginal branch of uterine artery, superior vesical artery, inferior epigastric or femoral \& deep circumflex illeal artery ${ }^{22}$; routine intravascular occlusion remain controversial. Methotrexate in the management of placental accreta was first described in $1986^{23}$. It is dihydrofolate reductase inhibitor that targets rapidly developing cells, most commonly used for the treatment of an ectopic pregnancy \& trophoblastic diseases. Some experts have used it as an adjunct to the conservative treatment of placenta accreta and also suggest that it helps rapid expulsion of placenta ${ }^{24}$. But methotrexate is contraindicated during breast feeding. Largest cohort reported no convincing evidence to currently support the efficacy of methotrexate in cases of placenta accreta left in situ and methotrexate related pancytopenia, nephrotoxicity are possible adverse effects ${ }^{25}$.

Management of unsuspected placenta percreta discovered during laparotomy

Delay the uterine incision if anything appears abnormal- distorted or ballooned lower segment, blood vessels of the uterine serosa, invasion of placenta into the bladder/surrounding tissues. Then assess location \& extent of placental invasion visually, evaluate the presence of active bleeding, inquire availability of blood, blood products, surgical assistance and equipments.

If the patient is stable and facilities is not currently prepared - cover the uterus with the laparotomy pack and await assistance and supplies, before proceeding with operative intervention, or fascial incision, place staple in skin and consider transfer to tertiary facilities with experienced in management of placenta accreta.

\section{Proposed criteria to identify failed trial of conservative management}

Ongoing haemorrhage despite conservative management (no limit, may be hours to weeks following delivery) cardiovascular instability or sign of haemorrhage shock, DIC (immediate/late). Identification at the time of delivery of any contraindications to conservative management (lateral to deep cervical invasion) development of complications as a result of conservative technique requiring abandonment of the approach (i.e. arterial injury, after attempted intra arterial ballon occlusion or embolization), severe pain following conservative management, maternal request to definitive surgical management (hysterectomy) after attempted conservative management ${ }^{26,27}$.

\section{Long term consideration}

Risk of recurrence after conservative management retrospective multi centred cohort sentilhes et. al. identify 21 of 96 women who undergone conservative management of accreta - later conceive. Of this 6 (29\%) have recurrence of accrete, 3 patient (14\%) had severe uterine synaechia $\&$ amenorrhoea. 1 case report of uterine rupture in pregnancy, following conservative management. To perform caesarean hysterectomy/ peripartum hysterectomy which need to be expertise \& team approach include trauma/ general surgeon, urologist also included in the team. ${ }^{28}$.

\section{Conclusion:}

Clearly planned, coordinated delivery $\&$ care help us to prevent morbidity \& mortality of women with placenta accreta. The importance of maintaining a high level of suspicion \& of early referral for antenatal imaging whenever accreta is suspected cannot be overstated. The combined team, a well resourced blood bank and a support of numerous nurses technologist and support of staff are truly lifesaving when it comes to placenta accreta.

\section{References:}

1. Khan KS,Wojdyla D ,Say L, Gulmezoglu AM, Van Look PF. WHO analysis of causes of maternal death : a systematic review. Lancet 2006; 367;1066-74.

2. Wortman AC,Alexander JM. Placenta accreta, increta \& percreta. Obstet Gynecol clin North Am 2013;40:137-54.

3. Mckeogh RP, D'Errico E, Placenta accreta, clinical manifestation \& conservative management.N Engl J Med 1951;245: 159-65.

4. Wu S, Kocherginsky M, Hibbard JU. Abnormal placentation : Twenty -year analysis .Am J Obstet Gynecol 2005 ; 192: 1458 61.

5. Silver RM ,Landon MB, Rouse DJ,et.al. Maternal morbidity associated with multiple repeat caesarean deliveries. Obstet Gynaecol 2006; 107 :1373-81.

6. Silver, Placenta accreta : Centre of excellence . Am J Obstet Gynecol 2015.

7. Berkley EM ,Abuhamad AZ, Prenatal diagnosis of placenta accreta ; is sonography all we need? J Ultrasound Med 2013;32:1345-50.

8. Gielchinsky Y, Mankuta D, Rozansky N, et al. Perinatal outcome of pregnancies complicated by placenta accreta .Obstet Gynecol $2004 ; 104: 527-30$. 
9. Reddy UM, Abuhamad AZ, Levine D, Saade GR; Fetal Imaging Workshop Invited Participants. Fetal Imaging : executive summary of a joint Eunice Kennedy Shiver National Institute of Child Health \& Human Development, Society for Maternal Fetal Medicine, American Institute of Ultrasound in Medicine ,American college of Obstetricians \& Gynaecologist, American college of Radiology, Society for Paediatric Radiology , \& Society of Radiologist in Ultrasound Fetal Imaging workshop. J Ultrasound Med 2014; 33; 745-57.

10. Fitzpatrick KE, Sellers S, Spark P, Kurinczuk JJ, Brocklehurst P, Knight M. The management \& outcome of placenta accreta, increta, \& percreta, in UK: a population -based descriptive study. BJOG 2014;121:62-70.discussion 70-1.

11. Perez-Delboy A, Wrigth JD, Surgical management of placenta accreta, - to leave / or remove the placenta? BJOG 2014; $121 ; 163$ -9. discussion 169-70.

12. Robinson BK, Grobman WA, Effectiveness of timing strategy for delivery of individual of placenta previa/accreta. Obstet Gynecol 2010;107,116:595-600.

13. ShamshirarsazAA, Fox K, Salmanian B, et al, Maternal morbidity in patient with morbid adherent placenta, treated with \& without a standardize multidisciplinary approach. Am J Obstet Gynecol $2015 ; 212: 218$.e 1-9.

14. Bowman ZS, Manuck TA, Eller AG, et al, Risk factor for unscheduled delivery in placenta accreta. Am J Obstet Gynecol 2014; 210, 241.e 1-6

15. Sentithes L, Goffinet F, Kayem G . Management of placenta accreta . Acta Obstet Gynecol Scand 2013 ; 92;1125-34.

16. Legendre G, Zoulovits FJ, Kinn J, Sentheles L, Fernandez H ,Conservative management of placenta accreta, hysteroscopic resection of retained tissues. J Minimally Invasive Gynecol $2014 ; 21 ; 910-3$

17. Sentithes L, Ambroselli C, Kayem G, et al, Maternal outcome after conservative treatment of placenta accreta, Obstet Gynecol 2010, 115, 526-34.
18. Clausen C, Lonn L, Langhoff-Roos J, Management of placenta percreta, a review of published cases. Acta Obstet Gynecol scand 2014; 93; 138-43.

19. Palacios Jaraquemada JM, Pesaresi M, Nassif JC, Hermosid S, Anterior placenta percreta ; surgical approach, hemostasis, and uterine repair. Acta Obstet Gynecol Scand 2004 ; 83,738-44.

20. Chandrafaran E, Rao S, Belli AM, Arukumaran S. The Triple P procedure as a conservative surgical alternative to peripartum hysterectomy for placenta percreta . Int. J Gynae Obstet 2012; $117: 191-4$

21. Teixidor Vinas M, Chandraharan E, Moneta MV, Belly AM, The role of interventional radiology in reducing haemorrhage \& hysterectomy, following caesarean section for morbid adherent placenta. Clin Radiol 2014; 69: e 345-51.

22. Clausen C, Stensballe J, Albrechtsen CK, Hansen MA,Lonn L, Langhoff Roos J ,Ballon occlusion of the internal iliac arteries in the multidisciplinary management of placenta percreta, Acta Obstet Gynecol Scand 2013 ; 92: 386-91.

23. Arulkumaran S, Ng CS, Ingemersson I, Ratnam SS, Medical treatment of placenta accreta with methotrexate. Acta Obstet Gynecol Scand 1986; 65:285-6.

24. Cirpan T, Sanhal CY, Yucibilgin S,Ozsener S, Conservative management of placenta previa percreta by leaving placental tissue in situ in situ with arterial ligation \& adjuvant methotrexate therapy . J Turk Ger Gynecol Assoc 2011; 12:127-9.

25. Sentihes L, Keam G, Ambroselly C, et al Fertility \& pregnancy outcome following conservative treatment of placenta accreta . Human Reproduc 2010;25:2803-10.

26. Pri-Paz S, Fuchs KM, Gaddipati S, et al, Comparison between emergent \& elective delivery, in women with placenta accreta, J. Matern Fetal Neonatal Med 2013,26:1007-11.

27. Silver RM, Landon MB, Rous DJ, et al, Maternal morbidity associated with multiple repeat caesarean sections . Obstet Gynecol 2006,107:1226-31.

28. Deshpandi NA, Carusi DA, Uterine rupture after conservative management of placenta accreta . Obstet Gynecol 2013, 122,(2pt 2)475-8. 